\title{
Orientações sobre o Documento de Área da CAPES - quesitos, indicadores e critérios
}

\section{PROPOSTA DO PROGRAMA}

A proposta de um programa de alta qualificação deve evidenciar de forma clara a coerência e consistência entre a área básica, as áreas de concentração e as linhas de pesquisa. Deve apresentar uma proporção adequada entre a quantidade e abrangência das áreas de concentração, linhas e projetos de pesquisa. Deve haver consonância entre a formação e atuação dos docentes e estrutura curricular. A produção intelectual deve apresentar vínculo estreito com os projetos e linhas de pesquisa. A proporção entre docentes, pesquisadores, discentes-autores e outros participantes deve ser adequada. É importante ressaltar os intercâmbios com instituições de ensino e pesquisa, como também com o setor produtivo nacional e internacional.

\section{CORPO DOCENTE}

O corpo docente deve ser constituído em sua totalidade por doutores, sendo mais de $80 \%$ deles em NRD6 e mais 90\% com envolvimento em atividades de ensino, pesquisa e orientação. O envolvimento deve ser de forma sistemática, com distribuição equilibrada das atividades entre todos os docentes.

A formação e vida acadêmica dos docentes componentes do núcleo de referência docente (NRD) devem atender a especificidade e abrangência das áreas de concentração, linhas e projetos de pesquisa e disciplinas do programa. Deve mostrar atividades letivas e de orientação na graduação. Os docentes devem apresentar produção científica regular, com pelo menos uma publicação/ano na forma de livros, capitulos de livros ou artigos em periódicos arbitrados e indexados, nacionais ou internacionais pertinentes à área em Qualis A e B. Adicionalmente devem apresentar trabalhos em reuniões científicas de pesquisa nacionais ou internacionais e publicados em anais.

O corpo docente deve ser de reconhecida projeção com participação em comitês, assessorias e comissões em órgãos de pesquisa e ensino, participação em corpo editorial de periódicos e comitês científicos de congressos e associações nacionais e internacionais.

\section{ATIVIDADES DE PESQUISA}

As linhas e projetos de pesquisa devem estar vinculados à proposta do programa. A presença de projetos isolados deve estar condicionada a uma efetiva contribuição ao programa ou que apresentem potencial para criação de linhas de pesquisa. Deve existir uma adequada quantidade de linhas e projetos de pesquisa em andamento. Tanto as linhas quanto os projetos de pesquisa devem guardar relação estreita entre a dimensão e qualificação do corpo docente. Os projetos de pesquisa devem apresentar a participação de discentes, quer seja do programa, quer seja discente da graduação. Preferencialmente os projetos devem apresentar financiamento de órgãos de fomento (CNPq, FAPs, etc).

\section{ATIVIDADE DE FORMAÇÃO}

A estrutura curricular deve mostrar adequação e abrangência em relação à(s) área(s) de concentração, com as linhas e projetos de pesquisa; as disciplinas deverão permitir sólida formação acadêmica científica e ser constantemente atualizada; a carga letiva deve estar distribuida entre todos os docentes do programa.

O oferecimento das disciplinas deve ocorrer em número e regularidade suficientes para assegurar o cumprimento dos planos de estudo dentro dos prazos preconizados pela CAPES.

\section{CORPO DISCENTE}

O corpo discente deve ser compatível com o tamanho e qualificação do corpo docente NRD6.

A média máxima discente por docente é $5: 1$. Os discentes devem ter orientadores desde o primeiro momento em que são admitidos no programa, o que permitirá cumprir os prazos de integralização estabelecidos pela CAPES. Os discentes deverão participar da produção intelectual do programa, fazendo apresentação em eventos científicos. O número de titulados deverá ser superior a $60 \%$ dos alunos existentes no início do ano base.

\section{TESES E DISSERTAÇÕES}

As teses e dissertações devem mostrar vínculo com as linhas de pesquisa que, por sua vez, devem estar inseridas na área de concentração do progra- 
ma; o tempo médio de titulação deverá ser igual ou menor que 24 meses para mestrado e 36 meses para o doutorado.

As bancas examinadoras devem contar com a presença de membros externos à unidade de no mínimo $1 / 3$ e $2 / 5$ para mestrado e doutorado respectivamente.

\section{PRODUÇÃO INTELECTUAL}

A produção intelectual deve apresentar coerência com a proposta do programa em qualidade e quantidade e deve refletir o envolvimento regular discente e docente em projetos de pesquisa. A produção intelectual deverá estar publicada em periódicos que caracterizem difusão dos conhecimentos que extrapolem limites locais, regionais e, se possível, nacional. Os docentes NRD6 deverão publicar obrigatoriamente, ao menos 1 trabalho completo/ano relacionados com a(s) área(s) de concentração, em periódicos indexados e arbitrados em níveis A e B. A produção intelectual deve apresentar regularidade e coerência com a proposta do programa, com as linhas de pesquisa e áreas de concentração. Deve refletir o envolvimento regular de discentes e docentes em projetos de pesquisa. As publicações consideradas adequadas são: artigos completos em periódicos indexados em bancos de dados internacionais, livros, capítulo de livros e patentes vinculados às teses e dissertações, linhas e projetos de pesquisa. Assim, para notas 6 e 7 quanto à produção intelectual foi considerada apenas a produção de autoria de docentes NRD6 do programa. Os artigos publicados foram classificados de acordo com o Qualis da CAPES. Os periódicos internacionais com indice de impacto igual ou maior que 0,8 foram classificados como A, mediana da área de Odontologia, e periódicos com índice de impacto abaixo de 0,8, como Qualis B.

Relação entre produção intelectual mínima no triênio e conceitos de avaliação:

a) Programa nota 7: $80 \%$ ou mais dos docentes (NDR6 e NDR7) publicaram no mínimo 4 artigos em Qualis internacional A e/ou B, sendo pelo menos 3 em Qualis A internacional.

b) Programa nota 6: $80 \%$ ou mais dos docentes (NDR6 e NDR7) publicaram no mínimo 3 artigos em Qualis internacional A e/ou B, sendo pelo menos 1 em Qualis A internacional.

c) Programa nota 5: $80 \%$ ou mais dos docentes (NDR6 e NDR7) publicaram no mínimo 3 artigos em Qualis nacional A ou B, sendo pelo menos $20 \%$ da produção total dos docentes NDR6 e
NDR7 publicada em periódicos Qualis internacional A ou B.

d) Programa nota 4: $70 \%$ ou mais dos docentes (NDR6 e NDR7) publicaram no mínimo 4 artigos em Qualis nacional A ou B.

e) Programa nota 3: 60\% ou mais dos docentes (NDR6 e NDR7) publicaram no mínimo 3 artigos em Qualis nacional A ou B.

f) Programa nota 2: $50 \%$ ou mais dos docentes (NDR6 e NDR7) publicaram no mínimo 2 artigos em Qualis nacional A ou B.

g) Programa nota 1: as demais situações.

Quesitos de avaliação/nota do curso/programa:

a) Somente serão avaliados para obter notas 6 e 7 os programas com nota 5 que em todos os quesitos de avaliação obtiveram o conceito muito bom.

b) Para obtenção de nota 5 o programa apresentou no mínimo 4 quesitos avaliados como muito bom, sendo que necessariamente deverão estar contemplados com este conceito os quesitos corpo docente, atividades de pesquisa e produção intelectual.

c) Para obtenção de nota 4, os quesitos corpo docente, atividade de pesquisa e produção intelectual deverão necessariamente ter conceito bom.

d) Para obtenção de nota 3, os quesitos corpo docente, atividade de pesquisa e produção intelectual deverão ter no mínimo conceito regular.

e) Para o quesito proposta do programa, cuja avaliação somente pode ser adequada ou inadequada, ficou estabelecida a tendência dada pelo próprio programa informatizado da CAPES: adequado ou inadequado (ver Quadro sinótico).

Ainda em relação aos quesitos para a inserção internacional dos programas de excelência (notas 6 e 7) há os itens de presença obrigatória e os de presença desejável:

\section{Inserção internacional}

\section{Presença obrigatória}

1. Publicações internacionais em periódicos com indice de impacto (Journal Citation Reports JCR);

2. Doutorados sanduíches;

3. Intercâmbio internacional demonstrado através de fomento internacional, programa de cooperação internacional, publicações em conjunto dos grupos parceiros. 


\section{Presença desejável}

1. Participação em corpo editorial de revistas de circulação internacional (Science Citation Index - SCI);

2. Participação como convidado em eventos científicos internacionais (cursos, conferências, palestras e bancas);
3. Docentes e alunos outorgados com prêmios acadêmicos internacionais;

4. Inserção de alunos estrangeiros no programa (mestrado, doutorado e pós-doutorado);

5. Patentes.

QUADRO SINÓTICO - relação dos quesitos, conceitos e avaliação do programa.

\begin{tabular}{|c|c|c|c|c|c|c|c|}
\hline \multirow[b]{2}{*}{ Nota } & \multicolumn{7}{|c|}{ Quesitos } \\
\hline & $\begin{array}{c}\text { Proposta do } \\
\text { programa }\end{array}$ & $\begin{array}{l}\text { Corpo } \\
\text { docente }\end{array}$ & $\begin{array}{l}\text { Atividades de } \\
\text { pesquisa }\end{array}$ & $\begin{array}{l}\text { Atividade de } \\
\text { formação }\end{array}$ & $\begin{array}{c}\text { Corpo } \\
\text { discente }\end{array}$ & $\begin{array}{c}\text { Teses e } \\
\text { dissertações }\end{array}$ & $\begin{array}{l}\text { Produção } \\
\text { intelectual }\end{array}$ \\
\hline 7 & $\mathrm{AD}$ & MB & MB & $\mathrm{MB}$ & MB & MB & EX \\
\hline 6 & $\mathrm{AD}$ & MB & MB & MB & MB & MB & EX \\
\hline 5 & $\mathrm{AD}$ & MB & MB & $\mathrm{MB} / \mathrm{B}^{*}$ & $\mathrm{MB} / \mathrm{B}^{*}$ & $\mathrm{MB} / \mathrm{B}^{*}$ & MB \\
\hline 4 & $\mathrm{AD}$ & $\mathrm{B}$ & $\mathrm{B}$ & $\mathrm{B} / \mathrm{R}^{* *}$ & $\mathrm{~B} / \mathrm{R} * *$ & $\mathrm{~B} / \mathrm{R} * *$ & $\mathrm{~B}$ \\
\hline 3 & $\mathrm{AD}$ & $\mathrm{R}$ & $\mathrm{R}$ & $\mathrm{R} / \mathrm{F}^{* * * *}$ & $\mathrm{R} / \mathrm{F}^{* * *}$ & $\mathrm{R} / \mathrm{F}^{* * *}$ & $\mathrm{R}$ \\
\hline 2 & IN & $\mathrm{R} / \mathrm{F}^{* * * *}$ & $\mathrm{R} / \mathrm{F} * * * *$ & $\mathrm{~F}$ & $\mathrm{~F}$ & $\mathrm{~F}$ & $\mathrm{R} / \mathrm{F}^{* * * * *}$ \\
\hline 1 & IN & I & I & I & I & I & I \\
\hline
\end{tabular}

$\mathrm{AD}$ = adequada; $\mathrm{IN}=$ inadequada $; \mathrm{EX}=$ excelente; $\mathrm{MB}=$ muito bom; $\mathrm{B}=$ bom; $\mathrm{R}=$ regular; $\mathrm{F}=$ fraco; $\mathrm{I}=$ insuficiente *Pelo menos 1 destes quesitos deverá ter conceito MB. ${ }^{* *}$ Pelo menos 2 destes quesitos deverão ter conceito B. ***Pelo menos 2 destes quesitos deverão ter conceito R. ${ }^{* * * *}$ Pelo menos 2 destes quesitos deverão ter conceito R. 
QUESITOS, INDICADORES E CRITÉRIOS PARA A AVALIAÇÃO TRIENAL Grande área de Ciências da Saúde

\begin{tabular}{|c|c|}
\hline \multicolumn{2}{|r|}{ I - Proposta do programa } \\
\hline Itens & Critérios \\
\hline \multicolumn{2}{|c|}{1 - Coerência e consistência da proposta do programa. } \\
\hline $\begin{array}{l}\text { Base epistemológica; } \\
\text { denominação do programa. }\end{array}$ & $\begin{array}{l}\text { Verificar se mantém: coerência com a área básica explicitada de forma clara e objetiva; } \\
\text { se é coerente com a tradição acadêmica e/ou profissional da área básica de } \\
\text { conhecimento. }\end{array}$ \\
\hline \multicolumn{2}{|c|}{2 - Adequação e abrangência das áreas de concentração. } \\
\hline $\begin{array}{l}\text { Área de concentração em } \\
\text { relação à proposta do } \\
\text { programa. }\end{array}$ & Verificar se apresentam: profundidade, abrangência e equilíbrio. \\
\hline \multicolumn{2}{|c|}{3 - Adequação e abrangência das linhas de pesquisa. } \\
\hline $\begin{array}{l}\text { Linhas de pesquisa em relação } \\
\text { às áreas de concentração. }\end{array}$ & $\begin{array}{l}\text { Verificar se apresentam: profundidade, abrangência e equilíbrio. } \\
\text { Coerência com a tradição acadêmica e/ou profissional da área básica de conhecimento. }\end{array}$ \\
\hline \multicolumn{2}{|c|}{4 - Proporção de docentes, pesquisadores, discentes-autores e outros participantes. } \\
\hline $\begin{array}{l}\text { Recursos humanos; } \\
\text { número e qualificação de } \\
\text { docentes e pesquisadores. }\end{array}$ & $\begin{array}{l}\text { Analisar se a proporção dos recursos humanos envolvidos no programa é adequada } \\
\text { para: a condução das atividades das áreas de concentração/linhas de pesquisa e o } \\
\text { atendimento da carga horária exigida. }\end{array}$ \\
\hline \multicolumn{2}{|l|}{5 - Infra-estrutura. } \\
\hline $\begin{array}{l}\text { Laboratórios; bibliotecas; } \\
\text { recursos de informática; } \\
\text { apoio financeiro de órgãos de } \\
\text { fomento. }\end{array}$ & $\begin{array}{l}\text { Laboratórios com condições para a realização das dissertações e teses; } \\
\text { bibliotecas permitem acesso rápido às informações, com ênfase nos periódicos; } \\
\text { recursos de informática disponíveis para alunos e docentes; } \\
\text { apoio técnico-financeiro de fundação de apoio à pesquisa (FAP) e instituição para a } \\
\text { condução de projetos de pesquisa. Demonstrar a existência de recursos próprios para a } \\
\text { realização de suas atividades e } \\
\text { capacidade de captação de recursos para o desenvolvimento para suas atividades de } \\
\text { pesquisa. }\end{array}$ \\
\hline 6 - Evolução. Atendimento de suge & stões anteriores. \\
\hline
\end{tabular}


Orientações sobre o Documento de Ârea da CAPES - quesitos, indicações e critérios. Pesqui Odontol Bras 2003;17(Supl 1):23-32.

\begin{tabular}{|c|c|}
\hline \multicolumn{2}{|l|}{ II - Corpo docente } \\
\hline Itens & Critérios \\
\hline \multicolumn{2}{|l|}{1 - Composição e atuação do corpo docente; vínculo institucional e dedicação. } \\
\hline $\begin{array}{l}\text { Titulação do corpo docente total; } \\
\text { atuação do corpo docente total em atividades de ensino, pesquisa e orientação; } \\
\text { distribuição da atuação equilibrada entre todos os docentes; } \\
\text { atuação de docentes externos para complementação das atividades de pesquisa, } \\
\text { de docência e de orientação. }\end{array}$ & $\begin{array}{l}\text { MB }=80-100 \% \text { de doutores; } \\
B=70-79 \% \text { de doutores; } \\
R=60-69 \% \text { de doutores; } \\
F=50-59 \% \text { de doutores; } \\
\text { I }=50 \% \text { ou }- \text { de doutores. }\end{array}$ \\
\hline \multicolumn{2}{|l|}{2 - Dimensão do NRD6/7 relativamente ao corpo docente. Atuação do NRD6/7. } \\
\hline Proporção de NRD6/7 em relação ao total do corpo docente. & $\begin{array}{l}M B=80-100 \% \text { de NRD6} \\
B=70-79 \% \text { de NRD6; } \\
R=60-69 \% \text { de NRD6; } \\
F=50-59 \% \text { de NRD6} \\
I=50 \% \text { ou }- \text { de NRD6. }\end{array}$ \\
\hline $\begin{array}{l}\text { Proporção de NRD6/7 com atuação em docência, orientação, publicação } \\
\text { e pesquisa. }\end{array}$ & $\begin{array}{l}\mathrm{MB}=90 \% \text { ou }+ \text { do NRD6/7 } \\
\mathrm{B}=75-89 \% \text { do NRD6/7; } \\
\mathrm{R}=60-74 \% \text { do NRD6/7; } \\
\mathrm{F}=50-59 \% \text { do NRD6/7 } \\
\mathrm{I}=50 \% \text { ou }- \text { do NRD6/7 }\end{array}$ \\
\hline Distribuição da atuação equilibrada entre os NRD6/7. & Análise qualitativa. \\
\hline \multicolumn{2}{|c|}{3 - Abrangência, especialização do NRD6/7 relativamente às áreas de concentração e linhas de pesquisa. } \\
\hline $\begin{array}{l}\text { Especialização e abrangência da formação do NRD6/7 em relação às áreas de } \\
\text { concentração, com ênfase nas linhas de pesquisa, levando-se em conta também } \\
\text { as disciplinas. }\end{array}$ & $\begin{array}{l}\text { MB = } 90-100 \% \text { de NRD6 } \\
\text { compatíveis; } \\
\text { B = 85 - 89\% de NRD6 } \\
\text { compatíveis; } \\
\text { R = 80 - 84\% de NRD6 } \\
\text { compatíveis; } \\
\text { F = 75 - 79\% de NRD6 } \\
\text { compatíveis; } \\
\text { I = 75\% ou - de NRD6 } \\
\text { compatíveis. }\end{array}$ \\
\hline NRD6/7 com reconhecida projeção acadêmica. & $\begin{array}{l}\text { Análise qualitativa quanto à } \\
\text { participação em ou como: conselho } \\
\text { editorial de periódicos; } \\
\text { consultor ad hoc de instituições } \\
\text { oficiais de fomento à pesquisa; } \\
\text { convidado para ministrar } \\
\text { conferência/palestra/cursos em } \\
\text { eventos acadêmicos de impacto } \\
\text { nacional/internacional. }\end{array}$ \\
\hline \multicolumn{2}{|l|}{4 - Intercâmbio ou renovação do corpo docente. Participação de outros docentes. } \\
\hline $\begin{array}{l}\text { Participação de docentes externos em atividades do curso: docência, } \\
\text { orientação, projetos de pesquisa etc. }\end{array}$ & $\begin{array}{l}\text { Análise qualitativa: verificar se a } \\
\text { participação de outros docentes } \\
\text { caracteriza enriquecimento ou } \\
\text { dependência. }\end{array}$ \\
\hline $\begin{array}{l}\text { Docentes do programa em treinamento, intercâmbio com pesquisadores } \\
\text { ou docentes de outras instituições de ensino superior. }\end{array}$ & Análise qualitativa. Recomendado. \\
\hline
\end{tabular}




\begin{tabular}{|c|c|}
\hline \multicolumn{2}{|r|}{ III - Atividades de pesquisa } \\
\hline Itens & Critérios \\
\hline \multicolumn{2}{|c|}{1 - Adequação e abrangência dos projetos e linhas de pesquisa em relação às áreas de concentração. } \\
\hline $\begin{array}{l}\text { Relação entre projetos de pesquisa, } \\
\text { linhas de pesquisa e áreas de } \\
\text { concentração. }\end{array}$ & $\begin{array}{l}\text { As linhas de pesquisa devem ter projetos de pesquisa em andamento e } \\
\text { concluídos; } \\
\text { as linhas de pesquisa devem apresentar clara delimitação e coerência com a } \\
\text { proposta do programa e áreas de concentração. }\end{array}$ \\
\hline \multicolumn{2}{|l|}{2 - Vínculo entre linhas e projetos de pesquisa. } \\
\hline & $\begin{array}{l}\text { MB }=90 \% \text { ou }+ \text { de projetos vinculados } \\
\mathrm{B}=80-89 \% \text { de projetos vinculados; } \\
\mathrm{R}=70-79 \% \text { de projetos vinculados } \\
\mathrm{F}=60-69 \% \text { de projetos vinculados; } \\
\mathrm{I}=60 \% \text { ou }- \text { de projetos vinculados. }\end{array}$ \\
\hline \multicolumn{2}{|c|}{$\begin{array}{l}3 \text { - Adequação da quantidade de linhas e projetos de pesquisa em andamento em relação à dimensão e qualificação do } \\
\text { NRD6/7. }\end{array}$} \\
\hline $\begin{array}{l}\text { Envolvimento de NRD6/7 por linha e } \\
\text { projeto de pesquisa. }\end{array}$ & $\begin{array}{l}\text { Análise qualitativa: pelo menos } 80 \% \text { dos projetos de pesquisa devem } \\
\text { estar sob a responsabilidade de um docente NRD6/7; } \\
\text { as linhas de pesquisa devem apresentar vinculação de, pelo menos } 2 \\
\text { projetos de pesquisa. } \\
\text { Todos os docentes NRD6/7 devem apresentar vinculação com projetos } \\
\text { de pesquisa. }\end{array}$ \\
\hline \multicolumn{2}{|c|}{4 - Participação do corpo discente nos projetos de pesquisa. } \\
\hline $\begin{array}{l}\text { Participação regular dos discentes nos } \\
\text { projetos de pesquisa. }\end{array}$ & $\begin{array}{l}\mathrm{MB}=80 \text { a } 100 \% \text { dos projetos de pesquisa com participação discente; } \\
\mathrm{B}=\text { de } 75-79 \% \text { dos projetos de pesquisa com participação discente; } \\
\mathrm{R}=\text { de } 70-74 \% \text { dos projetos de pesquisa com participação discente; } \\
\mathrm{F}=\text { de } 65-69 \% \text { dos projetos de pesquisa com participação discente; } \\
\mathrm{I}=<65 \% \text { dos projetos de pesquisa com participação discente. }\end{array}$ \\
\hline \multicolumn{2}{|c|}{5 - Financiamento. Participação em programas institucionais de fomento; outras fontes. } \\
\hline $\begin{array}{l}\text { Existência de projetos financiados por } \\
\text { agências de fomento e através de apoios } \\
\text { por programas de outras fontes. }\end{array}$ & $\begin{array}{l}\text { Análise qualitativa, verificando a existência de captação de recursos } \\
\text { financeiros para o desenvolvimento de projetos de pesquisa. }\end{array}$ \\
\hline \multicolumn{2}{|c|}{6 - Desenvolvimento de linhas e projetos de pesquisa colaborativos e interinstitucionais. } \\
\hline $\begin{array}{l}\text { Existência de intercâmbio interinstitu- } \\
\text { cional em atividades de pesquisa e do- } \\
\text { cência. }\end{array}$ & $\begin{array}{l}\text { Análise qualitativa, verificando o grau de intercâmbio interinstitucional. Este } \\
\text { deverá ser avaliado através das atividades de pesquisa e docência, traduzidas } \\
\text { por programas de cooperação e publicação com grupos parceiros. }\end{array}$ \\
\hline
\end{tabular}




\begin{tabular}{|c|c|}
\hline \multicolumn{2}{|c|}{ IV - Atividades de formação } \\
\hline Itens & Critérios \\
\hline \multicolumn{2}{|c|}{$\begin{array}{l}1 \text { - Adequação e abrangência da estrutura curricular relativamente à proposta do programa e às suas áreas de concentração. } \\
\text { Adequação e abrangência das disciplinas ministradas em relação às linhas e projetos de pesquisa. }\end{array}$} \\
\hline $\begin{array}{l}\text { Vinculação das disciplinas às áreas de } \\
\text { concentração e linhas de pesquisa. }\end{array}$ & $\begin{array}{l}\text { Análise qualitativa: compatibilidade e equilíbrio das disciplinas } \\
\text { à(s) áreas(s) de concentração e linhas de pesquisa. }\end{array}$ \\
\hline Profundidade e atualidade. & $\begin{array}{l}\text { Análise qualitativa: profundidade compatível com stricto sensu; } \\
\text { deve refletir os avanços na área. }\end{array}$ \\
\hline Abrangência da formação acadêmico-científica. & $\begin{array}{l}\text { Análise qualitativa: deve incluir disciplinas e/ou atividades } \\
\text { de formação científica e didático-pedagógica. }\end{array}$ \\
\hline Oferta compatível com prazos de titulação. & $\begin{array}{l}\text { MB = de } 80-100 \% \text { das disciplinas oferecidas no triênio; } \\
\text { B = de } 65-79 \% \text { das disciplinas oferecidas no triênio; } \\
\mathrm{R}=\text { de } 50-64 \% \text { das disciplinas oferecidas no triênio; } \\
\mathrm{F}=\text { de } 35-49 \% \text { das disciplinas oferecidas no triênio; } \\
\mathrm{I}=35 \% \text { ou }- \text { das disciplinas oferecidas no triênio. }\end{array}$ \\
\hline \multicolumn{2}{|c|}{$\begin{array}{l}2 \text { - Distribuição da carga letiva e carga horária média compatível com a dimensão do NRD6/7. } \\
\text { Participação de outros docentes. }\end{array}$} \\
\hline \multicolumn{2}{|c|}{ Análise quantitativa: cada NRD6/7 deverá ter oferecido disciplinas pelo menos 2 vezes no triênio. } \\
\hline \multicolumn{2}{|c|}{$\begin{array}{l}3 \text { - Quantidade de orientadores do NRD6/7 relativamente à dimensão do corpo docente. } \\
\text { Distribuição da orientação entre os docentes e número médio de orientados por docente. }\end{array}$} \\
\hline $\begin{array}{l}\text { Proporção de NRD6/7 com atividade de orientação. } \\
\text { Distribuição da orientação entre os docentes. }\end{array}$ & $\begin{array}{l}\text { MB }=80-100 \% \text { de orientadores NRD6/7; } \\
B=70-79 \% \text { de orientadores NRD6/7; } \\
\text { R = } 60-69 \% \text { de orientadores NRD6/7; } \\
F=50-59 \% \text { de orientadores NRD6/7; } \\
\text { I }=50 \% \text { ou }- \text { de orientadores NRD6/7. }\end{array}$ \\
\hline Distribuição da orientação entre o total de docentes. & $\begin{array}{l}\text { Análise qualitativa: verificar a existência de concentração } \\
\text { de orientados/docentes. }\end{array}$ \\
\hline Número médio de orientados por docentes. & $\begin{array}{l}\mathrm{MB}=\text { até } 5 \text { orientados; } \\
\mathrm{B}=\text { até } 6 \text { orientados; } \\
\mathrm{R}=\text { até } 7 \text { orientados; } \\
\mathrm{F}=\text { até } 8 \text { orientados; } \\
\mathrm{I}=8 \text { ou }+ \text { orientados. }\end{array}$ \\
\hline \multicolumn{2}{|c|}{4 - Atividades letivas e de orientação nos cursos de graduação. } \\
\hline $\begin{array}{l}\text { Participação dos NRD6/7 em disciplinas da } \\
\text { graduação. }\end{array}$ & $\begin{array}{l}\text { MB }=\text { de } 80-100 \% \text { de NRD } 6 / 7 \\
\text { B = } 70-79 \% \text { de NRD6/7; } \\
\text { R = } 60-69 \% \text { de NRD6/7; } \\
\text { F }=50-59 \% \text { de NRD6/7; } \\
\text { I = 50\% ou }- \text { de NRD6/7 }\end{array}$ \\
\hline
\end{tabular}




\begin{tabular}{|c|c|}
\hline \multicolumn{2}{|c|}{ V - Corpo discente } \\
\hline Itens & Critérios \\
\hline \multicolumn{2}{|l|}{1 - Dimensão do corpo discente em relação à dimensão do NRD6/7. } \\
\hline Média máxima de alunos por orientadores NRD6/7. & $\begin{array}{l}\text { MB }=\text { até } 5 \text { alunos; } \\
\text { B = } 5-6 \text { alunos; } \\
\text { R = } 6-7 \text { alunos; } \\
\text { F = } 7-8 \text { alunos; } \\
\text { I }=8 \text { ou }+ \text { alunos. }\end{array}$ \\
\hline \multicolumn{2}{|c|}{2 - Número de orientados em relação à dimensão do corpo discente. } \\
\hline & $\begin{array}{l}\text { MB }=90-100 \% \text { de orientados em relação ao corpo } \\
\text { discente; } \\
B=85-89 \% \text { de orientados em relação ao corpo discente; } \\
R=80-84 \% \text { de orientados em relação ao corpo discente; } \\
F=75-79 \% \text { de orientados em relação ao corpo discente; } \\
\mathrm{I}=75 \% \text { ou - de orientados em relação ao corpo discente. }\end{array}$ \\
\hline \multicolumn{2}{|c|}{3 - Número de titulados e proporção de desistência e abandono em relação à dimensão do corpo discente. } \\
\hline $\begin{array}{l}\text { Porcentagem de alunos titulados em relação à dimensão } \\
\text { do corpo discente considerando os prazos de titulação } \\
\text { para mestrado e/ou doutorado. }\end{array}$ & $\begin{array}{l}\text { MB = titulação de } 60 \% \text { do alunado; } \\
\text { B = titulação entre } 50 \text { - } 59 \% \text { do alunado; } \\
\text { R = titulação entre } 40 \text { - } 49 \% \text { do alunado; } \\
\text { F = titulação entre } 30 \text { - } 39 \% \text { do alunado; } \\
\text { I = titulação de } 30 \% \text { ou - do alunado. }\end{array}$ \\
\hline \multicolumn{2}{|c|}{4 - Número de discentes-autores da pós-graduação em relação à dimensão do corpo discente. } \\
\hline $\begin{array}{l}\text { Publicações de artigos, resumos e apresentações de } \\
\text { trabalhos de pesquisa em eventos científicos. }\end{array}$ & $\begin{array}{l}\text { MB = de } 80-100 \% \text { de alunos-autores; } \\
\text { B = de } 65-79 \% \text { de alunos-autores; } \\
\text { R = de } 50-64 \% \text { de alunos-autores; } \\
\text { F = de } 35-49 \% \text { de alunos-autores; } \\
\text { I = 35\% ou }- \text { de alunos-autores. }\end{array}$ \\
\hline \multicolumn{2}{|l|}{5 - Atividades de integração pós-graduação e graduação. } \\
\hline $\begin{array}{l}\text { Indicação de integração contemplando outras atividades } \\
\text { que não as obrigatórias previstas para bolsistas CAPES. }\end{array}$ & $\begin{array}{l}\text { Análise qualitativa: bolsas de iniciação científica, } \\
\text { participação de alunos de graduação em publicações } \\
\text { e apresentações em eventos científicos. }\end{array}$ \\
\hline
\end{tabular}




\begin{tabular}{|c|c|c|}
\hline \multicolumn{3}{|c|}{ VI - Teses e dissertações } \\
\hline Itens & \multicolumn{2}{|c|}{ Critérios } \\
\hline \multicolumn{3}{|c|}{$\begin{array}{l}1 \text { - Vínculo das teses e dissertações com áreas de concentração e com linhas e projetos de pesquisa. } \\
\text { Adequação ao nível dos cursos. }\end{array}$} \\
\hline Vínculo com a linha e projeto de pesquisa. & \multicolumn{2}{|c|}{$\begin{array}{l}\text { MB } \geq 90 \% \text { de compatibilidade; } \\
B \geq 80-89 \% \text { de compatibilidade; } \\
R \geq 70-79 \% \text { de compatibilidade; } \\
F \geq 60-69 \% \text { de compatibilidade; } \\
I<60 \% \text { de compatibilidade. }\end{array}$} \\
\hline \multicolumn{3}{|c|}{$\begin{array}{l}2 \text { - Tempo médio de titulação de bolsistas. Tempo médio de bolsa. } \\
\text { Relação entre médios de titulação de bolsista e não bolsista. }\end{array}$} \\
\hline \multirow{2}{*}{$\begin{array}{l}\text { Relação entre conceito e tempo de titulação em } \\
\text { meses. }\end{array}$} & Mestrado & Doutorado \\
\hline & $\begin{array}{l}\text { MB = até } 24 \text { meses; } \\
\mathrm{B}=\text { de } 25 \text { a } 30 \text { meses; } \\
\mathrm{R}=\text { de } 31 \text { a } 36 \text { meses; } \\
\mathrm{F}=\text { de } 37 \text { a } 42 \text { meses; } \\
\mathrm{I}=+ \text { de } 42 \text { meses. }\end{array}$ & $\begin{array}{l}\text { MB = até } 48 \text { meses; } \\
\mathrm{B}=\text { de } 49 \text { a } 54 \text { meses; } \\
\mathrm{R}=\text { de } 55 \text { a } 60 \text { meses; } \\
\mathrm{F}=\text { de } 61 \text { a } 66 \text { meses; } \\
\mathrm{I}=+ \text { de } 66 \text { meses. }\end{array}$ \\
\hline \multicolumn{3}{|c|}{3 - Número de titulados em relação à dimensão do NRD6/7. Participação de outros docentes. } \\
\hline & \multicolumn{2}{|c|}{$\begin{array}{l}\text { MB }=80-100 \% \text { de NRD6/7 com alunos titulados; } \\
\text { B = 75 }-79 \% \text { de NRD6/7 com alunos titulados; } \\
\text { R = 70-74\% de NRD6/7 com alunos titulados; } \\
F=65-69 \% \text { de NRD6/7 com alunos titulados; } \\
\text { I = }<65 \% \text { de NRD6/7 com alunos titulados. }\end{array}$} \\
\hline \multicolumn{3}{|c|}{4 - Qualificação das bancas examinadoras. Participação de membros externos. } \\
\hline Qualificação da banca examinadora & \multicolumn{2}{|l|}{$\begin{array}{l}\text { MB = } 100 \% \text { doutores; } \\
\mathrm{R}=99 \% \text { de doutores; } \\
\mathrm{I}=98 \% \text { de doutores }\end{array}$} \\
\hline $\begin{array}{l}\% \text { de participantes externos em bancas } \\
\text { examinadoras }\end{array}$ & \multicolumn{2}{|c|}{$\begin{array}{l}\text { MB } \geq 33 \% \text { de membros externos (mestrado), } \\
M B \geq 40 \% \text { de membros externos (doutorado); } \\
\text { B entre } 30-32 \% \\
\text { R entre } 27-29 \% \\
\text { F entre } 24-26 \% \\
\text { I } \leq \text { de } 24 \%\end{array}$} \\
\hline
\end{tabular}




\begin{tabular}{|c|c|}
\hline \multicolumn{2}{|c|}{ VII - Produção intelectual } \\
\hline Itens & Critérios \\
\hline \multicolumn{2}{|c|}{$\begin{array}{l}1 \text { - Adequação dos tipos produção à proposta do programa e vínculo com as áreas de concentração, } \\
\text { linhas e projetos de pesquisa ou teses e dissertações. }\end{array}$} \\
\hline $\begin{array}{l}\text { Vinculação da produção às linhas de pesquisa, } \\
\text { projetos, teses e dissertações. }\end{array}$ & $\begin{array}{l}M B=80-100 \% \\
B=70-79 \% \\
R=60-69 \% \\
F=50-59 \% \\
I=50 \% \text { ou }-\end{array}$ \\
\hline \multicolumn{2}{|l|}{2 - Adequação dos veículos ou meios de divulgação. } \\
\hline $\begin{array}{l}\text { Trabalhos completos (artigos, livros, capítulos e anais) } \\
\text { em veículos de qualidade A e/ou B. }\end{array}$ & $\begin{array}{l}M B=80-100 \% \\
B=70-79 \% \\
R=60-69 \% \\
F=50-59 \% \\
I=50 \% \text { ou }-\end{array}$ \\
\hline \multicolumn{2}{|c|}{3 - Quantidade e regularidade em relação à dimensão e do NRD6/7. Distribuição da autoria entre os docentes. } \\
\hline $\begin{array}{l}\text { Quantidade e regularidade de publicação anual de artigos } \\
\text { completos em periódicos Qualis A/B, livros, capítulos de } \\
\text { livro com ISBN, entre os docentes NRD6/7. }\end{array}$ & $\begin{array}{l}M B \geq 1,5 \\
B=1,3-1,4 \\
R=1,0-1,2 \\
F=0,7-0,9 \\
I<0,7\end{array}$ \\
\hline $\begin{array}{l}\text { Distribuição da publicação de artigos completos em } \\
\text { periódicos Qualis A/B, livros, capítulos de livros com } \\
\text { ISBN, entre os docentes NRD6/7. }\end{array}$ & $\begin{array}{l}M B=80-100 \% \\
B=70-79 \% \\
R=60-69 \% \\
F=50-59 \% \\
I<50 \%\end{array}$ \\
\hline \multicolumn{2}{|l|}{4 - Autoria e co-autoria de discentes. } \\
\hline $\begin{array}{l}\text { Relação entre porcentagem de discentes } \\
\text { autores e publicações. }\end{array}$ & $\begin{array}{l}\text { MB = } 80-100 \% \text { de discentes-autores; } \\
B=70-79 \% \\
R=60-69 \% \\
F=50-59 \% \\
I<50 \%\end{array}$ \\
\hline
\end{tabular}

